\title{
Development of an Occupational Performance Questionnaire for pre- school children with Autistic Spectrum Disorder
}

\author{
Kerry Wallace, BSc (OT) UCT, MSc OT (Wits) \\ Clinical Director, Polkaspot Early Intervention Centre, \\ Postgraduate Student, Occupational Therapy Department, School of Therapeutic Sciences, Faculty of Health Sciences, University \\ of the Witwatersrand
}

\section{Denise Franzsen, BSc OT (Wits), MSc OT (Wits), DHT (Pret)}

Senior Lecturer, Department of Occupational Therapy, School of Therapeutic Sciences, Faculty of Health Sciences, University of the Witwatersrand

\section{Joanne Potterton, BSc Physio (Wits), MSc Physio (Wits), PhD (Wits)}

Associate Professor, Department of Physiotherapy, School of Therapeutic Sciences, Faculty of Health Sciences, University of the Witwatersrand

Background and Aim: Outcome measures in occupational therapy (OT) are needed to provide evidence of the effectiveness of OT intervention. The aim of this study was to develop an occupational performance assessment specific to preschool children with Autistic Spectrum Disorder (ASD).

Methodology: An instrument development design was used to describe the steps in the development of the Occupational Performance Questionnaire (OPQ) which consisted of two parts:- Part I General Information, Part 2, OPQ: Occupational Performance Areas (OPQ:OPA) and OPQ: Family Impact (OPQ: FI). Content, construct and convergent validity, test-retest reliability and internal consistency for the OPQ was established. The OPQ was field tested with parents of 19 pre-schoolers with ASD receiving weekly OT intervention, who completed the OPQ three times over a one year period.

Results: Content analysis confirmed the appropriateness of the items and the OPQ was responsive to change over time for the OPQ:OPA and OPQ:FI. Convergence of the OPQ:OPA with the Short Sensory Profile (SSP) and the OPQ:FI with the Parent Stress Index (PSI-SF) was moderate to weak. The items on the OPQ had test-retest reliability and internal consistency at acceptable levels.

Conclusions: The OPQ is an inexpensive, parent report outcome measure appropriate for use with South African pre-school children with ASD designed to evaluate change in their OPAs over time. Further research in psychometric analysis and standardisation of the $O P Q$ is recommended.

Key words: Autism Spectrum Disorder, Psychometric evaluation, Occupational Performance, Preschool children. Parent report outcome measure

\section{INTRODUCTION}

Since the prevalence of Autism Spectrum Disorder (ASD) in South Africa is unknown', the Association for Autism makes use of the international prevalence rate which is reported to be $1: 42$ for boys I:I89 for girls².

In line with international practice the diagnosis of young children with ASD in South Africa is based on a lack of social participation with a poor use of non-verbal behaviours such as eye contact and a lack of emotional and spontaneous behaviour during social interaction. Little or no verbal behaviour or verbal communication is also characteristic of $\mathrm{ASD}^{3}$ with a higher incidence of children with no verbal ability being reported in the South African context ${ }^{4}$. Repetitive and stereotyped behaviour is common and in a study in the Western Cape, problematic behaviour in young children with ASD was indicated as a major concern. Eighty nine percent of parents reported challenging behaviours, with stereotypical movements $(62 \%)$, hyperactivity $(43 \%)$ and sleep disturbance $(32.8 \%)$ being the behaviours causing the most anxiety ${ }^{4}$.

Rehabilitation therapy and education services for ASD in South Africa are limited ${ }^{5}$. In rural areas the condition often goes undiagnosed until the child starts to attend school ${ }^{6}$. Even once a diagnosis is made there is very limited access to special schooling with only nine ASD-specific schools and a few non-governmental and private pre-schools for ASD in South Africa ${ }^{5}$. Children, on average, face a 3-6 year waiting list to get a place in an ASD-specific school, ${ }^{7,8}$.

Therefore, particularly at the pre-school stage, most parents rely on therapy services in an under- resourced public healthcare sector and non-profit organisations for support and intervention. However, as $48 \%$ of South Africans earn less than US\$2 a day ${ }^{9}$, and only the few families from the $16 \%$ of the population who have medical aid are able to afford expensive private therapy ${ }^{10,11}$ so access to education and rehabilitation is limited. Occupational therapy (OT) services therefore vary from weekly intervention, to monthly or bi-monthly clinic visits with the provision of home programmes.

Therapists need to ensure that their services are effective and tasks are continued at home. The development of outcome measures, such as the Occupational Performance Questionnaire (OPQ) can be used to indicate change in occupational performance areas (OPAs) in pre-school children with ASD. The positive changes then serve as a motivation for the families to continue intervention. Measuring the effectiveness OT services is important not only for the professional practice but can be used to motivate for appropriate services and OT staff.

\section{LITERATURE REVIEW}

Presently there is a lack of evidence to support that OT intervention offered to children with ASD does indeed lead to improved occupational performance ${ }^{12}$. Therapists therefore need valid outcome 
measures to assess the effectiveness of intervention for occupational performance ${ }^{13}$. The deficits in all OPAs seen in pre-school children with ASD are specific to the condition and include problems such as restrictive eating (related to type and texture of food), delayed toilet training and irregular sleep-wake cycles. Deficits are also seen in an inability to play with peers and limited social participation (in terms of both interaction and communication). In addition sleep ${ }^{14}$ and eating disorders ${ }^{15}$ have been associated with sensory processing disorders indicating that occupational performance may be related to the high-over and -under responsive sensory modulation in these children ${ }^{16}$.

The lack of independence in OPAs in children with ASD can result in prolonged dependency on others, which affects not only the child's quality of life, but also that of their family ${ }^{17-21}$. Research indicates that family functioning is affected by the child's poor sleep patterns, having to constantly plan ahead due to routinised and ritual behaviours, giving up family outings and holidays due to the child's behaviour and dependence and one or both parents having their careers interrupted by the child's need for care ${ }^{17}$. The affected family functioning can result in marital and family conflict with positive and negative effects on other children in the family ${ }^{18}$. Addressing delays in OPAs can therefore assist the families with the considerable stress that having a child with ASD places on parents, caregivers and family functioning ${ }^{19}$. The effect that the lack of ability in the OPAs of pre-school children with ASD, has on family functioning is difficult to measure objectively since families perceive their challenges differently. Furthermore the spectrum of mild to severe presentation of ASD is another variable relating to the child's individual differences in sensory processing, their emotional developmental level and their level of OPA functioning and the support that they receive from caregivers ${ }^{16,20,21}$.

Little research has been published on improvement in the OPAs of children with ASD, although assessing changes in these areas have been documented as being important for parents ${ }^{22}$. Previous research pertaining to outcomes in OT interventions for children with ASD has considered changes in the client factors and performance skills related to sensory processing and development, but not the progress made in the areas of occupation. The research emphasis in OT therefore has not been on an occupation based assessment approach, but on the use of other relevant standardised measures with pre-school children with ASD. These include tests of sensory processing and developmental scales such as the Sensory Integration and Praxis Test (SIPT) ${ }^{23}$, the Sensory Profile and Short Sensory Profile (SSP) ${ }^{24}$ and the Bayley Developmental Scales III25.

Although standardised outcome measures and assessment tools for assessing occupational performance in children, including the Canadian Occupational Performance Measure (COPM $)^{26}$ and the Pediatric Evaluation of Disability Inventory (PEDI) ${ }^{27}$ are available, they do not investigate problems related to behaviour specifically seen in children with ASD. These measures evaluate parent satisfaction with activities and use parent reported information of the child's ability in OPAs. Standardised outcome measures evaluating family quality of life, health and stress are also available and include the Care-Related Quality of life instrument (CarerQol) ${ }^{28}$ for parents of children with ASD and the Parent Stress Index (PSI) ${ }^{29}$. However, no outcome measure that considers the effect of dysfunction in the occupational performance of children with ASD on family functioning directly ${ }^{30}$ could be found.

Furthermore due to the cost and the fact that published outcome measures are not standardised on a South African population, they are often not used by occupational therapists in South Africa. Occupational therapists usually establish initial interview data on OPAs from parents'/care-giver's narrative history and clinical observations. These observations of preschool children, out of their normal context, in a short assessment period, do not always provide the therapist with a true reflection of the child's abilities and behaviour. Since parents have a better knowledge of their child's abilities, with the guidance of the items on a questionnaire, they could provide a more accurate and complete picture of the child and the family functioning. This information could then be used to inform occupational therapy intervention ${ }^{31}$.

No available inexpensive, parent report outcome measure, to assess the OPAs of pre-school children with ASD and the effect that their dysfunction/abilities in their OPA's may have on their families, could be found. The aim of the study was therefore to develop an inexpensive parent report outcome measure to assess the OPAs of personal activities of daily living (PADL), sleep, play, and social participation in children with ASD and the impact of the child's dysfunction in their OPAs on the family's functioning.

\section{METHODS}

The methodology of this study is based on instrument design which follows specific steps. The Occupational Performance Questionnaire (OPQ) was developed in three steps, based on a process described in the literature ${ }^{32,33}$

Step I: Development of the OPQ: Development of items was based on review of the literature and other measures to define the constructs and domains, specify the type of measure and prepare and format the items.

Step 2: Confirmation of items used a descriptive survey design with experts in the subject and focus groups with members of the target population to determine content validity and appropriateness of the items of the OPQ as well as test-retest reliability of the OPQ.

Step 3: Obtaining data by field testing used a longitudinal repeated assessment design with the parents of pre-school children between 3-6 years with ASD who were receiving weekly occupational therapy, to confirm construct validity for responsiveness to change and internal consistency as well as convergent validity to other standardised outcome measures.

\section{Participants}

No participants were required for Step I of the study.

In finalising the items and determining the content validity of the OPQ in Step 2, three occupational therapists considered subject matter experts, were purposively selected to review the OPQ. The therapists met the following inclusion criteria: practising in the field of paediatrics and had at least 10 years' experience in providing OT services to children with ASD. Four parents of pre-school children with ASD who were receiving occupational therapy ${ }^{34}$ were also recruited to determine content validity.

A further five parents of pre-school children with ASD who were receiving OT were recruited to complete the test-retest component of the study in Step 2.

In Step 3, nineteen parents of pre-school children aged 3-6 years, with ASD were enrolled in the study to determine construct validity in relation to responsiveness to change as well as the convergent validity of the OPQ. The inclusion criteria were that the parents were willing for their child to start and continue with OT for one year, and the child met the DSM $V$ diagnostic criteria for ASD as confirmed by a child psychiatrist, and had no visible physical impairments. Children diagnosed with severe cognitive deficits were also excluded.

\section{Ethics}

Approval for this study was obtained from the Human Research Ethics Committee at the University of the Witwatersrand. An information letter was provided and signed consent was obtained from all participants in the study.

\section{Measuring instruments}

The Occupational performance Questionnaire (OPQ) was used to measure the change in occupational performance of preschool children with ASD and the effect that their ability in occupational performance had on family functioning over a one year period.

The Short Sensory Profile (SSP) ${ }^{24}$ is a caregiver questionnaire, consisting of 38 items that measured sensory modulation during 
daily life. It has been standardised on both typically developing children and children with developmental disabilities. It has construct validity and occupational relevance and good internal reliability $(0.70 \text { to } 0.90)^{35}$. The SSP is used as a measure of change and adaptive ability in the ASD population, who demonstrate significantly different sensory processing patterns ${ }^{36}$. Sensory processing has been associated with performance in a number of areas of occupation ${ }^{14,15}$.

The Parent Stress Index, Short Form (PSI-SF) ${ }^{29}$ is a 36-item, selfreport questionnaire/interview which assesses Total Stress as well as Parental Distress, Parent-Child Dysfunctional Interaction and Difficult Child subtests. The index has good internal consistency $(0.80$ to 0.91$)$ and test-retest reliability $(0.68$ to 0.85$)$ for the various subtests ${ }^{29}$.

\section{Research procedure}

For Step I in order to define the construct and the domains to be included in the outcome measure the developmental milestones for the pre-school age group that were commonly delayed in children with ASD were determined from the literature ${ }^{19,35,37-39}$. The type of items and layout of international outcome measures were also reviewed ${ }^{26,27,29,40}$. A second construct that considered the effects of the child's ability in occupational performance on family functioning ${ }^{19,21,28,41}$ was included in line with the familycentred intervention for ASD. Once the key constructs and domains of the OPQ had been identified from a literature review ${ }^{15,20,42}$ and the clinical experience of the researcher, items were selected which targeted deficits in the child's OPAs and the impact of these deficits on family life. The OPQ was scored on a Likert scale of I - 5 with I equivalent to Almost never and 5 equivalent to Almost always ${ }^{32}$. A higher score indicated greater achievement in terms of reaching appropriate milestones in the given occupational performance areas, and a lower effect on family functioning.

The content of the OPQ items was refined through a phased approach in Step 2. The draft copy of the OPQ was e-mailed to the three occupational therapists who met the inclusion criteria. They were requested to review the items and scoring on the OPQ to ensure that items were appropriate, relevant, clear and understandable, that the items were correctly divided into the occupational performance areas (OPQ:OPA) and family impact (OPQ:FI) and that the scores for the OPA indicated age appropriate milestones in occupational performance.

Four mothers of pre-school children with ASD receiving OT reviewed the items on the OPQ for content validity. They were included in a discussion group and asked to consider the applicability, specificity and relevance of the items for pre-school children with ASD, and commented on how the items were constructed as well as the scoring suggested.

Based on the input from the occupational therapists and the mothers, modifications were made to the OPQ. The corrected version of the OPQ was assessed for test-retest reliability by five parents of pre-school children. Test-retest reliability was important as the OPQ was to be used in repeated measures in field testing and so the parents were asked to complete the OPQ at OT sessions twice, two weeks apart.

The construct validity in terms of responsiveness to change of the OPQ was established in Step 3 as well as the convergent validity to other standardised tests traditionally used to assess client factors in children with ASD, the SSP and PSI-SF. Nineteen parents of pre-school children with ASD completed the OPQ, SSP and PSI-SF assessments three times, at the initiation of therapy and after six months and at one year. Their children attended weekly OT during this time.

\section{Data Analysis}

The following analyses were carried out:

* Demographic data on the children with ASD and their caregivers were analysed using descriptive statistics.
$*$ Test - retest reliability of the questionnaire was established by using the non-parametric Spearman's correlation coefficient. This co-efficient was used due to the ordinal nature of the data and the relatively small sample size.

* Construct validity was established by each subtest being used three times over the period of a year with the 19 participants and the results analysed. Firstly the responsiveness (construct validity) of the test to change was established by determining the significance of the change at six months and a year using the non-parametric Chi-squared test and standardised response means (SRMs) which is an effect size index used to measure the responsiveness of scales to clinical change ${ }^{43}$.

* Convergent validity was established by first totalling the scores for each item in the domains on the OPQ. These total scores from the initial interview were correlated with the total scores for the subtests on other standardised tests ie the Short Sensory Profile (SSP) ${ }^{24}$ and the Parent Stress Index, Short Form(PSI-SF ${ }^{29}$ using the Spearman's correlation co-efficient as the data on all tests was ordinal.

Data were analysed using MedCalc and Statistica v 12.

\section{RESULTS}

\section{STEP I: Development of the OPQ}

In Step I of the development of the OPQ the key construct was the occupational performance of pre-school children with ASD. The domains for the OPAs were based on those specified by the Occupational Therapy Practice Framework II (OTPF II) ${ }^{45}$ that were commonly found to be dysfunctional in in preschoolers with ASD. Based on the literature on occupational performance areas, the most affected in pre-school children with ASD were PADL ${ }^{15,46}$, sleep $^{14}$, social participation ${ }^{38}$ and play ${ }^{42}$ and these domains were used in the OPQ ${ }^{45}$. These domains were also considered according to developmental milestones in 4-6 year old children and behaviours affecting occupational performance in pre-school children with ASD. This included dysfunction in sensory processing, adherence to rituals and routines, the abnormal ability to focus on objects, hyperactivity and stereotypical mannerisms ${ }^{3}$. Interaction and communication under social participation was considered separately based on diagnostic criteria ${ }^{3}$ and due to the high incidence of non-verbal ASD children reported in South Africa ${ }^{4}$.

The second construct identified was the effect of the preschoolers occupational performance on family functioning based on the literature. This included how the parents' roles, careers, marital and family conflict and social participation were impacted by the ability of their child to perform in various activities ${ }^{13,22}$.

The format for the OPQ was then established ${ }^{32}$. The outcome measure was based on criterion referenced testing, where the child is his/her own control. This allowed for outcomes to be measured based on each child's level of development in different occupational performance tasks without comparing them to the developmental trajectory of typically developing children ${ }^{22}$ The OPQ was written in simple language, to accommodate the varied education levels and language differences of the caregivers in South Africa ${ }^{47}$. As suggested in the literature, progress in the occupational performance of pre-school children with ASD was measured from their parents' perspective ${ }^{31,48}$. Thus a caregiver report assessment appeared to be the best choice for measuring occupational performance outcomes for this population as well as the effect of the child's delay in occupational performance on family functioning ${ }^{49}$.

The scoring of the items allowed for measured changes in the occupational performance as a result of growth or progress made in therapy by individual children to be recorded. In children with a chronic condition such as ASD, six-monthly and annual evaluations should complement ongoing monitoring to compare the child's progress with a criterion-based standard for setting of therapy goals and outcomes achieved. 
Table I: Parts, domains and items on the Occupational Performance Questionnaire

\begin{tabular}{|c|c|c|}
\hline Parts & $\begin{array}{l}\text { Number of } \\
\text { Items }\end{array}$ & Sub Items \\
\hline Part I General Information & 23 items & $\begin{array}{l}\text { Marital status, occupation, family income of parents, gender, age, diagnosis, concurrent } \\
\text { supplementary interventions, details of age level for milestone achievement for sleeping } \\
\text { toilet training and tantrums, and details of schooling, }\end{array}$ \\
\hline \multicolumn{3}{|l|}{ Part 2} \\
\hline \multicolumn{3}{|c|}{ Occupational Performance Questionnaire :Occupational Performance Areas (OPQ:OPA)- construct } \\
\hline \multicolumn{3}{|l|}{ Domains } \\
\hline \multicolumn{3}{|l|}{ Personal Activities of Daily Living } \\
\hline $\begin{array}{l}\text { Toilet Training } \\
\text { Feeding }\end{array}$ & $\begin{array}{l}3 \text { Core items } \\
\text { (I Sub-item) } \\
12 \text { Core items }\end{array}$ & $\begin{array}{l}\text { Includes use of nappies during the day and night, accidents and bed-wetting. } \\
\text { Includes tolerance of textures and taste of food, problems with chewing, sucking, } \\
\text { swallowing and gagging as well as ability to sit through a meal and eat enough food. The } \\
\text { effect on family routine and harmony and parent distress caused by eating problems. }\end{array}$ \\
\hline \multicolumn{3}{|l|}{ Sleep } \\
\hline Sleeping & $\begin{array}{l}5 \text { Core items } \\
\text { (4 Sub- items) }\end{array}$ & $\begin{array}{l}\text { Includes sleeping problems, methods used to help the child to sleep, impact of sleep } \\
\text { routine on family harmony and interrupted sleep of family. }\end{array}$ \\
\hline \multicolumn{3}{|l|}{ Social Participation } \\
\hline $\begin{array}{l}\text { Individual } \\
\text { Peer Interaction } \\
\text { Group Interaction }\end{array}$ & $\begin{array}{l}6 \text { Core items } \\
(22 \text { Sub- items) } \\
12 \text { Core items } \\
5 \text { Core items }\end{array}$ & $\begin{array}{l}\text { Includes details of the child's aggressive behaviour and tantrums, self-stimulatory } \\
\text { behaviour, ability to cope with transitions, and cope in a variety of environments and } \\
\text { parents' responses to the child's dependency and difficulty with separations. } \\
\text { Includes child's responses to other children, taking turns, ability to seek help, imitate } \\
\text { others and make friends. } \\
\text { Includes the child's ability to cope with family and social gatherings, and the family's ability } \\
\text { to sustain relationships with others. }\end{array}$ \\
\hline \multicolumn{3}{|l|}{ Social Participation } \\
\hline Communication & 5 Core items & $\begin{array}{l}\text { Includes how the child communicates by talking, signing, making sounds, pointing or crying } \\
\text { and screaming. }\end{array}$ \\
\hline \multicolumn{3}{|l|}{ Play } \\
\hline $\begin{array}{l}\text { Individual } \\
\text { Group Play }\end{array}$ & $\begin{array}{l}7 \text { Core items } \\
2 \text { Core items } \\
\text { (7 Sub-items) } \\
7 \text { Core items }\end{array}$ & $\begin{array}{l}\text { Examples of developmental levels of play were provided to assist parents to assess } \\
\text { whether their child was functioning predominantly at a sensorimotor, concrete operations } \\
\text { level, whether there was social, representational or symbolic play. } \\
\text { Includes the types of play activities the child chooses of his/her own accord, and his/her } \\
\text { attention span during different activities. } \\
\text { Includes the child's participation in a variety of settings, and his/her ability to cope with } \\
\text { frustrations, engage in parallel play, and understand humour. }\end{array}$ \\
\hline $\begin{array}{l}\text { Occupational Performance } \\
\text { Questionnaire: Family Impact } \\
\text { (OPQ:FI) construct }\end{array}$ & $\begin{array}{l}6 \text { Core items } \\
\text { (8 Sub items) }\end{array}$ & $\begin{array}{l}\text { Includes the family members' responses to the child with ASD, parents' roles, marital } \\
\text { conflict, or withdrawal. }\end{array}$ \\
\hline
\end{tabular}

\section{STEP 2: Confirmation of items}

\section{Finalisation of items}

In Step 2 based on the input from the experts and members of the target population, some modifications were made to the OPQ to ensure content validity. No items were deleted. Feeding items and details of family impact were expanded based on input from the mothers in the focus groups specifying other dysfunctional behaviours of concern. The number of questions was increased to cover other specific behaviours related to ASD such as the number of times per night the child wakes and changes to the frequency of bed wetting. Scoring retained a 5 point Likert, with 5 (Almost always) showed normal performance while on other questions, a score of I (Almost never) indicated no or poor performance for the majority of items. On some items the Likert scale was related to a scale for the number of minutes or the number of times the behaviour occurred, including the length of time the child could stay at the dinner table, and to record their attention span. A scale to record the number of times the child woke at night was also added.

The corrected questionnaire took approximately 20 minutes to complete and consisted of two parts.

Part I was designed to obtain demographic details of the child and family as well as medical history and an occupational history profile to identify relevant milestones already achieved by the child with ASD $^{50}$.

Part 2, The OPQ: OPA covered the occupational performance construct and consisted of four sub-scales, PADL (toilet training and feeding) $)^{13}$, Sleep ${ }^{14}$, Social Participation (interaction at an individual, peer and group level as well as communication) ${ }^{38}$ and Play (level, individual and group) ${ }^{42}$ with a total of 90 items (Table $I$ ).

Part 3, OPQ: FI was the Family Impact (FI) section, which contained 12 questions based on the sub-construct of the effect of the child's ability in occupational performance on family functioning and was scored in one sub-scale (Table I).

\section{Test-retest reliability}

Preliminary test-retest reliability of the items on the final version of the OPQ was conducted over a two week period. The test-retest reliability assessed for these parents was high with domain correlations of between 0.66 and 0.97 being achieved and with the total item correlations of rho $=0.90$.

\section{STEP 3: Obtaining data by field testing}

The field testing in Step $\mathbf{3}$ was completed with 19 parents from a variety of socio-economic and cultural backgrounds. Demographic 
data indicated that $47 \%(9)$ of the parents did not have English as their home language, $21 \%(4)$ were single parents, $63 \%(12)$ came from lower socio-economic circumstances, with a mean monthly income of less than R6000. The cultural mix included the various population groups from the South African context with African children comprising 58\%(I I), Asian II \%(I) and 3I\%(7) of Caucasian origin. The gender mix for the children was $21 \%(4)$ females and $79 \%$ (15) males with a mean age of 4.04 years.

The total scores on the OPQ indicated that the children scored at $54 \%$ of the expected level of independence and while just under $50 \%$ were toilet trained for day and night.

\section{Construct validity - Responsiveness to Change}

In order to determine if the items on the OPQ could detect clinically important change over time ${ }^{33}$ standardised response means were established for the change that occurred over one year. The OPQ:OPA PADL was found to have improved significantly both at six months and one year with a large standardised response mean (SRM) of more than 0.80, while OPQ:OPA Play showed statistically significant change over the one year with a moderate standardised response mean over 0.50. The OPQ:OPA Social participation (interaction, and communication), Sleep and OPQ:FI scores did not improve significantly and the standardised response mean for these domains and constructs was below 0.50 which was small (seeTable II).

\section{Convergent Validity}

The convergent validity of the OPQ with other standardised tests ie the Short Sensory Profile (SSP) ${ }^{24}$ and the Parent Stress Index, Short Form(PSI-SF ${ }^{29}$ at initial assessment were analysed. All the children presented with SSP $\mathrm{z}$ scores on initial assessment that ranged from - I.74 to - 4.37 indicating moderate to severe sensory processing dysfunction. The parents in this study demonstrated high levels of parenting stress with a mean raw score of 104 on the PSI-SF at initial interview. (A raw score over 90 is considered to be clinically significant in terms of stress levels $\left.{ }^{29}\right)$.

The scores for the items in each domain of OPQ: OPA and the subtest scores on the Short Sensory Profile (SSP) ${ }^{24}$ were correlated for the initial assessment. The correlations between the initial scores on the OPQ:OPA and SSP scores were weak except for OPQ: OPA Play group, Social Interaction individual, Social Interaction group and the total score for the Social Interaction domian. The correlations between the OPQ: FI and PSI-SF scores on initial
Table III: Correlation of scores on the three outcome measures on initial assessment $(n=19)$

\begin{tabular}{|c|c|c|}
\hline \multicolumn{3}{|c|}{ Occupational Performance Questionnaire Domains } \\
\hline $\begin{array}{l}\text { OPQ:Occupational } \\
\text { Performance Areas }\end{array}$ & & Rho \\
\hline - Sleep & \multirow{15}{*}{$\begin{array}{l}\text { Short Sensory } \\
\text { Profile Total Score }\end{array}$} & -0.03 \\
\hline - Toilet & & -0.19 \\
\hline - Feed & & 0.05 \\
\hline $\begin{array}{l}\text { Total Personal } \\
\text { management }\end{array}$ & & -0.06 \\
\hline - Social Interaction individual & & 0.39 \\
\hline - Social Interaction peer & & \\
\hline - Peer & & -0.05 \\
\hline - Social Interaction group & & \\
\hline - Group & & 0.31 \\
\hline Total Social interaction & & 0.34 \\
\hline - Communication & & 0.08 \\
\hline - Play level & & -0.14 \\
\hline - Play Individual & & -0.14 \\
\hline - Play -Group & & 0.37 \\
\hline Total Play & & 0.03 \\
\hline \multirow{3}{*}{ OPQ: Family Impact } & $\begin{array}{c}\text { Parent Stress } \\
\text { Questionnaire } \\
\text { Parenting Distress }\end{array}$ & -0.60 \\
\hline & $\begin{array}{l}\text { Parent Stress } \\
\text { Questionnaire } \\
\text { Parent-Child } \\
\text { Interaction }\end{array}$ & -0.34 \\
\hline & $\begin{array}{l}\text { Parent Stress } \\
\text { Questionnaire } \\
\text { Difficult Child }\end{array}$ & -0.34 \\
\hline
\end{tabular}

Rho (r) $\quad 0.5-0.8$, Strong correlation.

0.3 - 0.5, Moderate correlation.

0.1 - 0.3, Weak correlation.

Table II: Change in scores and standardised response means on the Occupational Performance Questionnaire over one year $(n=19)$

\begin{tabular}{|c|c|c|c|c|c|c|}
\hline \multirow{2}{*}{ Domains } & \multirow{2}{*}{$\begin{array}{c}\text { Initial } \\
\text { Assessment } \\
\begin{array}{c}\text { Median (lower } \\
\text { and upper } \\
\text { quartile) }\end{array}\end{array}$} & \multirow{2}{*}{$\begin{array}{c}\text { Six months } \\
\begin{array}{c}\text { Median (lower } \\
\text { and upper } \\
\text { quartile) }\end{array}\end{array}$} & \multirow{2}{*}{$\begin{array}{c}\text { One year } \\
\begin{array}{c}\text { Median (lower and } \\
\text { upper quartile) }\end{array}\end{array}$} & \multicolumn{2}{|c|}{$p$ value } & \multirow{2}{*}{$\begin{array}{l}\text { Standardised } \\
\text { Response Mean } \\
\text { (SRM) }\end{array}$} \\
\hline & & & & $\begin{array}{c}\text { Initial } \\
\text { Assessment to } \\
\text { six months }\end{array}$ & $\begin{array}{c}\text { Initial } \\
\begin{array}{c}\text { Assessment to } \\
\text { one year }\end{array}\end{array}$ & \\
\hline $\begin{array}{l}\text { Personal activities } \\
\text { of daily living }\end{array}$ & $\begin{array}{c}85 \\
(64-91) \\
\end{array}$ & $\begin{array}{c}89 \\
(78-101) \\
\end{array}$ & $\begin{array}{c}93 \\
(79-89)\end{array}$ & $0.00 I^{*} * *$ & $0.00 * *$ & $1.13 * *$ \\
\hline Sleep & $\begin{array}{c}47 \\
(35-52) \\
\end{array}$ & $\begin{array}{c}44 \\
(39-53) \\
\end{array}$ & $\begin{array}{c}45 \\
(45-52) \\
\end{array}$ & $0.4 I$ & 0.06 & 0.46 \\
\hline $\begin{array}{l}\text { Social } \\
\text { participation } \\
\text { Interaction }\end{array}$ & $\begin{array}{c}110 \\
(105-132) \\
7\end{array}$ & $\begin{array}{c}117 \\
(96-142) \\
7\end{array}$ & $\begin{array}{c}|2| \\
(10|-| 46) \\
8\end{array}$ & $\begin{array}{l}0.42 \\
0.92\end{array}$ & $\begin{array}{l}0.09 \\
0.30\end{array}$ & $\begin{array}{l}0.35 \\
0.31\end{array}$ \\
\hline $\begin{array}{l}\text { Social } \\
\text { participation } \\
\text { Communication }\end{array}$ & $\begin{array}{c}7 \\
(4-10)\end{array}$ & $\begin{array}{c}7 \\
(4-10)\end{array}$ & $\begin{array}{c}8 \\
(5-\mid 4)\end{array}$ & 0.92 & 0.30 & 0.31 \\
\hline Play & $\begin{array}{c}83 \\
(72-95) \\
\end{array}$ & $\begin{array}{c}85 \\
(73-97) \\
\end{array}$ & $\begin{array}{c}90 \\
(79-104)\end{array}$ & 0.17 & $0.01 * *$ & $0.66 *$ \\
\hline Family Impact & $\begin{array}{c}38 \\
(25-46) \\
\end{array}$ & $\begin{array}{c}35 \\
(3 I-42) \\
\end{array}$ & $\begin{array}{c}44 \\
(3 \mid-48) \\
\end{array}$ & 0.84 & 0.24 & 0.42 \\
\hline \multicolumn{3}{|c|}{$\begin{array}{l}p \leq 0.05^{*} \text { significant } \\
p<0.0 I^{*} \text { highly significant }\end{array}$} & $\begin{array}{l}<0 \\
< \\
<<\end{array}$ & \multicolumn{2}{|c|}{$\begin{array}{l}<0.2=\text { small, } \\
<0.5=\text { moderate } \\
<0.8=\text { large }\end{array}$} & \\
\hline
\end{tabular}


assessment had a strong negative convergent validity for the PSI-SF subtest of parent distress as in the PSI-SF, high score indicate high stress and in the OPQ:FI, high score indicate low stress. The correlations with other subtests on the PSI-SF were weak and showed no convergent validity between the OPQ: FI and Parent-Child Interaction and Difficult child (Table III on page 27).

\section{Internal consistency}

Internal consistency of the items over the three assessment periods was also evaluated OPQ: OPA (Cronbach's alpha $=0.72$ ) and OPQ: FI (Cronbach's alpha $=0.9 \mathrm{I}$ ), indicating that these constructs demonstrate item consistency for this sample of South African children with ASD. Cronbach's alpha values for the individual domains of OPQ: OPAs ranged from acceptable to high for PADL and the individual and peer-group questions of OPQ: OPA Social Participation (Interaction), but were lower for OPQ: OPA Social Participation (Communication) and OPQ: OPA Play (Table IV).

Table IV: Occupational Performance Questionnaire: Item Internal consistency $(n=19)$

\begin{tabular}{|l|c|}
\hline Occupational Performance Components & Cronbach $\alpha$ \\
\hline Personal Management & 0.92 \\
\hline Toilet Training & 0.78 \\
\hline Feeding & 0.82 \\
\hline Sleep & 0.88 \\
\hline Social Participation & 0.76 \\
\hline Interaction Individual $\quad$ Geer Interaction & 0.65 \\
\hline \multicolumn{2}{|c|}{ Groupteraction } \\
\hline Communication & 0.56 \\
\hline Play & 0.62 \\
\hline Level of Play & 0.63 \\
\hline Individual & 0.58 \\
\hline Group Play & 0.91 \\
\hline Family Impact &
\end{tabular}

\section{DISCUSSION}

The OPQ was designed specifically to assess the occupational performance of preschool children with ASD, and included items to measure the effect that their diagnosis had on OPAs and family functioning. Content validity was established with the review of items by subject matter experts and mothers of children with ASD. Valuable information was added to the sleep and feeding items as a result of the input from the mothers of the children with ASD confirming the importance of consulting members of the target population when designing outcome measures for them ${ }^{34}$. This step ensured that the items identified from the literature included dysfunctional behaviours specific to ASD that are seen during the performance of occupations. These included night waking ${ }^{14}$, selfstimulatory behaviour (stimming), mouthing and spinning objects and tantrums which affected social participation and were of concern to the mothers of the children with ASD.

The OPQ was also found to be acceptable in terms of administration time and when used in this study no problem with response rates and missing data were experienced as none of the 19 parents dropped out of the study ${ }^{33}$. Although concerns about the validity of parent report questionnaires have been raised the OPQ addressed all the criteria suggested by Diamond and Squires ${ }^{35}$ to improve the accuracy of the parents input. The content of the questionnaire when assessing pre-school children was appropriate and the OPQ allowed parents to formally report on deficits specific to ASD and which related to their child's development. This has been shown to increase the validity of the reports. The parents were also asked to report on current OPA problems being experienced in the child's newly emerging skills, rather than recall previous incidents ${ }^{3 !}$.

The layout and ease of using the tick boxes was considered at the design stage which made the OPQ easy to fill out. Very short one to seven word items facilitated reading and understanding for parents who did not have English as a first language. It was found that language could be accommodated by assisting parents to complete the OPQ using an interview format ${ }^{47}$ and giving help by translating some words for them if necessary. This is an important feature of the OPQ which needs to be used with parents from a variety of backgrounds in the South African context.

The instrument was easy to administer and not reliant on a specific venue as it can be completed either at the therapy venue or the parents' home. Scoring on the five point scaling can be completed in a few minutes ${ }^{32}$ and the assessment can be used by therapists who have had no specific training in the administration of the OPQ. The time needed to complete the assessment and score it may be similar to or quicker than other occupational performance assessments such as the PEDI ${ }^{27}$.

The difficulty of items on the OPQ were acceptable in this age group as no participant scored at a floor or ceiling level on any of the items in OPQ: OPA. The items cover an appropriate range of abilities for preschool children with ASD in the areas of PADL, sleep, play and social participation. A similar finding for the OPQ:FI indicated that family functioning was affected in all the families on some items in the Family Impact construct ${ }^{13,22}$.

The longitudinal nature of the field testing of the OPQ allowed for further construct validity to be established in terms of its responsiveness to change. Research indicates that change in chronic conditions such as ASD when intervention is provided once week is likely to be modest thus any outcome measure used needs to be responsive to small changes ${ }^{13}$. The OPQ:OPA was responsive to change in all domains with those in PADL and play reaching significance over the period of one year. The standardised response mean for these two domains indicate high and moderate change of over the equivalent of more than one standard deviation for OPQ:OPA PADL and more than half a standard deviation for OPQ:OPA Play. Thus it can be accepted that the scoring for the PADL and play domains on the OPQ is sensitive to the relevant clinical change in children with ASD between the ages of 4 to 6 years and that the items can discriminate change adequately over time ${ }^{32}$.

The other domains on the OPQ:OPA Sleep and OPQ:OPA Social Participation did not change significantly over the one year period and were found to have small standardised response means. The change cannot be considered clinically relevant, since social participation is the greatest deficit seen in children with ASD and forms the basis of the criteria used to diagnose the condition ${ }^{3}$. The slower change on this domain over one year can therefore be expected. Sleep was another major concern of parents with children with $\mathrm{ASD}^{4}$ and the results of this study confirm that this is an aspect of occupational performance that also shows slower change over time. The scoring on these items therefore needs to be adjusted to be more sensitive to changes in behaviour allowing for smaller increments in behaviour to guide outcomes to be considered by the treating therapists.

The lack of correlation between the four domains PADL, sleep, play and social participation on the OPQ:OPA also indicate that the domains represented are all different from each other and are not interdependent. This confirms that each section should be scored and totalled separately. The OPQ:FI was considered to be a separate construct ${ }^{44}$.

While the OPQ:FI scores which had a small standardised response means and did not improve significantly over the one year period, this was congruent with the change on the PSI:SF where the scores did not drop below 90 , indicating that the parents still experienced clinically significant stress. Since ASD is a chronic condition, the child's dysfunction in occupational performance will continue to affect the family. 
The results indicate that convergent validity was strong between the OPQ: FI and PSI-SF parent distress, indicating an association between this subtest of the PSI-SF and the effect of the occupational performance of the child with ASD on family functioning. The OPQ: FI can be used to evaluate the impact that the child with ASD has on the family allowing for some assumptions about parental stress. The moderate correlations for OPQ:OPA and social integration and play in groups with improvement in tactile, visual and auditory sensitivity on the SSP may indicate that these sensory processing deficits affect behaviour in social situations and groups. However the low convergence between the other domains on the OPQ:OPA and the SSP suggest that occupational performance cannot be associated with the sensory processing of a child with ASD. This reflects the findings of Kane who also found a low correlation between these two variables ${ }^{37}$.

All domains and constructs on the OPQ were shown to be internally consistent and had acceptable test-retest reliability for the sample of children with ASD in this study and although play, communication and social interaction were slightly below the accepted level of 0.07 this is within the limits reported in most standardised tests ${ }^{32}$ This indicates that the items on the test are appropriate and that the sensitivity of the scoring of the items needs to still be addressed.

\section{Limitations of the research}

Although rigor was attempted in the field testing methodology, the small sample size has limitations particularly with regard to the internal validity of the study.

\section{Recommendations}

The OPQ can be used by clinicians to assess and determine the change in occupational performance with children with ASD in South Africa in terms of criteria set by Fitzpatrick et $\mathrm{al}^{51}$. The OPQ proved to be appropriate within the South African context, as a parent report outcome measure or in some cases conducted with the assistance in the format of a structured interview however the OPQ has not yet been standardised for the South African population but can serve as an interim measure. Further research on a larger sample of children with ASD is recommended to further refine and standardise the measure. It is also recommended that the OPQ be translated into other South African languages.

\section{CONCLUSION}

Early educational and health related intervention services for children with ASD in South Africa are inadequate. Occupational therapists can contribute to services for children with ASD through addressing personal and environmental barriers to performance and in the adaptation of occupations and environments.

The OPQ is an inexpensive, easily reproducible parent reported outcome measure and could provide clinicians with an outcome measure to determine the effectiveness of therapy in occupational performance dysfunction areas, specific for preschool children with ASD. These outcomes can then inform clinicians in the establishment of occupation based therapy goals and support home programmes. The measure allows for a family centred approach by addressing factors affecting family functioning related to the child's occupational performance areas. With further research and standardisation the OPQ, may be used to inform evidence-based practice in OT services for children with ASD in South Africa.

\section{ACKNOWLEDGEMENTS}

To all the children and parents who participated in the study. Dr P Becker, MRC, for assistance with statistical procedures.

\section{REFERENCES}

I. Association for Autism. "The State of Autism in RSA". 2012. < http:// afa.org.za/> (March 25 2016).

2. Christensen DL. Prevalence and characteristics of autism spectrum disorder among children aged 8 years - Autism and developmental disabilities monitoring network, I I sites, United States, 20 I 2. MMWR Surveillance Summaries, 2016; 65.

3. Charman T, Baird G. Practitioner review: Diagnosis of autism spectrum disorder in 2- and 3-year-old children. Journal of Child Psychology and Psychiatry, 2002; 43(3): 289-305.

4. Springer P, van Toorn I, Laughton I, Kidd M. Characteristics of children with pervasive developmental disorders attending a developmental clinic in the Western Cape Province, South Africa. South African Journal of Child Health, 2013; 7(3): 95-99.

5. Jacklin L, Stacey J, editors. Accessibility to Education for Autistic Children in South Africa, a Resource Limited Country. IX International Congress for Autism; 2010; Catania.

6. Grinker R, Chambers N, Njongwe N, Lagman A, Guthrie W, Stronach $S$, et al. "Communities" in community engagement: lessons learned from autism research in South Korea and South Africa. Autism Research, 2012; 5(3): 20I-210.

7. Pillay S. Sensory Compatibility of Children with Autism and their Mothers. Saarbrücken: Lambert Academic Publishing, 20II.

8. Geertsema S, Hyman C, van Deventer C. Short message service (SMS) language and written language skills: educators' perspectives. SA Journal of Education, 20I I; 3I (4): 475-486.

9. OECD. "OECD Economic Surveys: South Africa 20I3,”. OECD Publishing. 2013. <http://dx.doi.org/10.1787/eco_surveys-zaf20I3-en> (April I4 20I4).

10. Bateman C. Autism - mitigating a global epidemic. South African Medical Journal, 2013; 103(5): 276-277.

II. Statistics South Africa. Use of health facilities and levels of selected health conditions in South Africa: Findings from the General Household Survey, 20I I. Report No. 03-00-05 (20II): Pretoria: 2013.

12. Jacklin $L$. The changing profile of autism in a clinic for children with developmental delay. Pandagram, 2006; II (I): 2-3.

13. Miller-Kuhaneck H. Autism: A Comprehensive Occupational Therapy Approach. Baltimore: AOTA Press, 2004.

14. Reynolds S, Lane SJ. Research brief: Sensory responsiveness and problem sleep behaviors in children with autism spectrum disorders. Sensory Integration Special Interest Section Quarterly, 20I I; 34(I): I-4.

15. Provost B, Crowe TK, Osbourn PL, McClain C, Skipper BJ. Mealtime behaviors of preschool children: Comparison of children with autism spectrum disorder and children with typical development. Physical and Occupational Therapy in Pediatrics, 2010; 30(2): 220-233.

16. Dunn W. The Impact of Sensory Processing Abilities on the Daily Lives of Young Children and Their Families. A Conceptual Model. Infants and young Children, 1997; 9(4): 23-35.

17. Montes G, Halterman JS. Psychological functioning and coping among mothers of children with autism: A population-based study. Pediatrics, 2008; I 19(8): 1040-6.

18. Orsmond GI, Seltzer MM. Siblings of individuals with autism spectrum disorders across the life course. Mental Retardation and Developmental Disabilities Research Reviews, 2007; 13(2): 313-320.

19. Hayes S, Watson S. The Impact of Parenting Stress: A Meta-analysis of Studies Comparing the Experience of Parenting Stress in Parents of Children With and Without Autism Spectrum Disorder. Journal of Autism and Developmental Disorders, 2013; 43(3): 629-642.

20. Solomon R, Necheles J, Ferch C, Bruckman D. Pilot study of a parent training program for young children with autism: the PLAY Project Home Consultation program. Autism, 2007; II(3): 205-224.

21. Ludlow A, Skelly C, Rohleder P. Challenges faced by parents of children diagnosed with autism spectrum disorder. Journal of Health Psychology, 2012; 17(5): 702=11.

22. Rodger S, Braithwaite M, Keen D. Early Intervention for Children with Autism: Parental Priorities. Australian Journal of Early Childhood, 2004; 29(3): 34-4I.

23. Bodison S, Mailloux Z. The Sensory Integration and Praxis Tests. OT Practice, 2006; II (I7) 20-22.

24. Dunn W. Sensory Profile User's Manual. San Antonio: Psychological Corporation, 1999.

25. Bayley N. Bayley Scales of Infant and Toddler Development - Third Edition. San Antonio: Harcourt Assessment, 2006.

26. Law M, Baptiste S, Carswell-Opzoomer A, McColl M, Polatajko H, Pollock N. Canadian Occupational Performance Measure. Toronto: CAOT Publications, 1991.

27. Andrellos P, Coster W, Haley S, Haltiwanger J, Ludlow L. Introduc- 
tion to the PEDI. Pediatric Evaluation of Disability Inventory (PEDI). Boston: PEDI Research Group, 1998.

28. Brannan. AM, Heflinger. CA, L. B. The caregiver strain questionnaire measuring the impact on the family of living with a child with serious emotional disturbance. Journal of Emotional and Behavioral Disorders, 1997; 5(4): 212-222.

29. Abidin R. Parenting Stress Index: Professional Manual. Lutz, Florida: USA Psychological Assessment Resources Inc, 1995.

30. Hoefman R, Payakachat N, van Exel J, Kuhlthau K, Kovacs E, Pyne J, et al. Caring for a Child with Autism Spectrum Disorder and Parents' Quality of Life: Application of the CarerQol. Journal of Autism and Developmental Disorders, 2014; 44(8): 1933-1945.

31. Diamond K, Squires J. The role of parental report in the screening and assessment of young children. Journal of Early Intervention, 1993; 17(2): 107-II5.

32. Fawcett A. Principles of Assessment and Outcome Measurement for Occupational Therapists and Physiotherapists: Theory, Skills and Application. London: John Wiley \& Sons,, 2007.

33. Kielhofner G. Research in Occupational Therapy: Methods of Inquiry for Enhancing Practice; Developing and Evaluating Quantitative Data Collection Instruments. Philadelphia: FA Davis Co, 2006.

34. Vogt $D$, King D, King L. Focus groups in psychological assessment: enhancing content validity by consulting members of the target population. Psychological assessment, 2004; 16(3): 231-243.

35. Miller LJ, Coll J, Schoen S. A randomized controlled pilot study of the effectiveness of Occupational Therapy for Children with sensory modulation disorder. American Journal of Occupational Therapy, 2007; 6I(2): 228-238.

36. Baranek G, David F, Poe M, Stone W, Watson L. Sensory Experiences Questionnaire: discriminating sensory features in young children with autism, developmental delays, and typical development. Journal of Child Psychology and Psychiatry, 2006; 47 (6): 59I-60I.

37. Kane A. Sensory Modulation Disorder: Impact on Coping and Occupational Performance. Virginia Commonwealth University; 2013.

38. Sheperd J. Activities of Daily Living. In: Case-Smith J, O'Brien J, editors. Occupational Therapy for Children, 6th ed. Maryland Heights: Mosby; 20I0. p. 474-5I7.

39. Khanna R, Madhavan S, Smith M, PatrickJ, Tworek C, Becker-Cottrill $B$. Assessment of health-related quality of life among primary caregivers of children with autism spectrum disorders. Journal of Autism and Developmental Disorders, 201 I; 4I(9): I2I4-1227.

40. Jasmin E, Couture M, McKinley P, Reid G, Fombonne E, Gisel E. Sensori-motor and daily living skills of pre-school children with autism spectrum disorders. Journal of Autism and Developmental Disorders, 2009; 39(2): 23I - 24I.

4I. Herring S, Gray K, Taffe J, Tonge B, Sweeney D, Einfeld S. Behaviour and emotional problems in toddlers with pervasive developmental disorders and developmental delay: associations with parental mental health and family functioning. Journal of Intellectual Disability Research, 2006; 50(I2): 874-882.

42. Couch K, Deitz J, Kanny E. The role of play in pediatric occupational therapy. American Journal of Occupational Therapy, 1998; 52(2): III117.

43. Husted JA, Cook RJ, Farewell VT, Gladman DD. Methods for assessing responsiveness: a critical review and recommendations. Journal of Clinical Epidemiology, 2000; 53(5): 459-468.

44. Furr M, Bacharach V. Pychometrics: An Introduction. Thousand Oaks: Sage Publications Inc, 2008.

45. American Occupatioan Therapy Association. Occupational therapy practice framework: Domain and process 2 nd ed. American Journal of Occupational Therapy, 2008; 62(6): 625-683.

46. Miller L, Kinnealley $M$. Researching the Effectiveness of Sensory Integration. SI Quarterly, 2006; XXI(2): I-7.

47. Yeh Y-Y. Programmes to Increase Literacy in South Africa. Global Perspectives on Human Language:The South African Context, http:// web.stanford.edu/ jbaugh/saw/Yoo-Yoo_Literacy.html 2004.

48. Rydz D, Srour M, Oskoui M, Marget N, Shiller M, Birnbaum R, et al. Screening for developmental delay in the setting of a community pediatric clinic: a prospective assessment of parent-report questionnaires. Pediatrics, 2006; I I8(4): el I78-e I I86.

49. Rodger S, Polatajko H. Occupational Therapy for Children with Autism. In: Patel VB, Preedy V, Martin C, editors. Comprehensive Guide to Autism. New York: Springer 2014. p. 2297-23I4.
50. Schaaf R, Smith Roley S. SI: Applying Clinical Reasoning to Practice with Diverse Populations. San Antonio. Psychological Corporation, 2005.

5I. Fitzpatrick R, Davey C, Buxton M, Jones D. Evaluating patient-based outcome measures for use in clinical trials. Health Technology Assessment, 1998; 2(14): i-iv, I-74. 